\title{
Time Integration of Shallow Water Equations in the Gravity Wave Regime
}

\author{
By Hiroshi Tanaka* \\ National Center for Atmospheric Research,** Boulder, Colorado 80307 \\ (Manuscript received 19 October 1983, in revised form 23 December 1983)
}

\begin{abstract}
Time integrations of shallow water equations were carried out in order to investigate whether (inertio-) gravity waves are produced or not through upscale energy transfer due to nonlinear wave-wave interactions. Differing from the limitless upscale energy transfer occurred in pure two-dimensional turbulence, the results demonstrate that the upscale energy transfer is weak and is suppressed in the lower wavenumber domain. Initially given gravity waves with random amplitudes and phases produce somewhat inhomogeneous and wave-like patterns at the final decaying stage, which can be identified as large-scale (inertio-) gravity waves. This fact suggests that such nonlinear wave-wave interactions can be regarded as one of the candidates to produce large-scale waves. However, it cannot always be concluded definitely whether the process is an effective mechanism for generation of the large-scale gravity waves in the actual atmosphere or the oceans. Other features of shallow water waves appeared through the process of nonlinear interactiors are described in detail.
\end{abstract}

\section{Introduction}

In the past few years some workers have revealed that (inertio-) gravity waves play important roles on some aspects of atmospheric dynamics particularly in the middle atmosphere. These waves break into turbulence and produce drag forces to weaken zonal mean flows not only near the mesopause (cf. Lindzen, 1981 ; Holton, 1982 ; Matsuno, 1982 ; Dunkerton, 1982) but also near the tropopause (cf. Tanaka and Yamanaka, 1984).

Possible causes of the generation of such waves in the troposphere can be classified as, (i) mountains with various horizontal scales (e.g., Bretherton, 1969), (ii) shear instability associated with the jet stream (Klostermeyer, 1980), (iii) ageostrophic instability associated with the low level jet (Chen, 1982), (iv) energy cascade from synoptic disturbances (Matsuno,

* On leave from the Water Research Institute, Nagoya University, Chikusa-ku, Nagoya 464, Japan.

** The National Center for Atmospheric Research is sponsored by the National Science Foundation.
1979), and (v) upscale energy transfer from relatively small-scale disturbances (Gage, 1979 ; Balsley and Carter, 1982). Gravity waves of mountain origin could have the largest amplitudes throughout the mesoscale domain (20$2000 \mathrm{~km}$ ) and seem to break near the tropopause to produce weak region of zonal mean flow (Tanaka and Yamanaka, 1984). Other causes of wave generation mentioned in (ii), (iii) and (iv) must be examined with more efforts than ever both theoretically and observationally.

This paper aims at examining the upscale energy transfer through nonlinear wave-wave interactions in the gravity wave regime as mentioned in (v). In general, waves are motions of different kind from turbulence, that is, waves are propagation of patterns of fluid motions while turbulence is associated with the fluid motion itself. Major part of the waves would propagate away leaving weak nonlinear waves or turbulence through nonlinear interactions. Therefore, nonlinear interactions among waves are considered to be weaker 
than those in the pure two-dimensional turbulence.

So far numbers of efforts have been devoted to examine dynamics of the pure two-dimensional turbulence focusing on the upscale energy transfer through wavenumber domain (cf. Ogura, 1952; Kraichnan, 1967, 1971 ; Leith, 1968 ; Batchelor, 1969 ; Lilly, 1969, 1971 ; Herring et al., 1974). Main conclusions obtained by such a great number of papers are summarized as, (i) two-dimensional decaying turbulence finally approaches -3 power law throughout all the wavenumber domain, (ii) two-dimensional forced turbulence leads to $-5 / 3$ and -3 power laws in the lower and higher wavenumber domains than the forcing wavenumber, respectively. The active upscale energy transfer found in the two-dimensional turbulent motions is based on the enstrophy conservation, in addition to the energy conservation, in a specific domain. Geostrophic turbulence proposed by Charney (1971) is considered to be involved in a category of twodimensional turbulence, too.

In the atmosphere and the oceans there are wave motions like Rossby waves and/or gravity waves other than turbulence. A fluid system which contains waves and turbulence is more realistic as a model of the atmosphere and oceans than an idealized system of twodimensional turbulence. Investigations treating such a system were not found before the pioneering work by Rhines (1975). He carried out numerical simulations of two-dimensional turbulence on a beta-plane. The result clearly demonstrated that the upscale energy transfer from initially given smaller-scale random vortices is suppressed by generation of Rossby waves despite that both energy and enstrophy are conserved within the domain. This means that the conservations of enstrophy and energy do not always guarantee the limitless upscale energy transfer when waves are generated.

In this paper we treat (inertio-) gravity waves on an $f$-plane together with low amplitude geostrophic motions. A shallow water model is used for the numerical simulations instead of three-dimensional stratified fluid model, simply because we are interested in looking into essence of the nonlinear interactions avoiding the complexities accompanied by the vertical structures of waves. The situation considered here is as follows: when relatively smaller-scale random disturbances* are given at an initial moment, what kind of disturbances are finally produced through upscale energy transfer? Are the produced disturbances (inertio-) gravity waves or geostrophic motion eddies? Is the upscale energy transfer, if any, a powerful mechanism for generation of mesoscale gravity waves in the atmosphere and the oceans?

The shallow water model for the gravity wave regime seems more complicated than two-dimensional Rossby wave regime treated by Rhines (1975) in a sense that absolute enstrophy and potential enstrophy do not conserve within a specific domain though these conserve on a fluid parcel. Breakdown of the conservation property of them comes from permitting the change of shallow water depth, i.e., weak three-dimensionality. Therefore, extensive upscale energy cascades should be prohibited in principle. Another possibility considered in the shallow water gravity wave regime is triad (or resonant) interactions among waves, which are characterized by discontinuous amplifications of energy spectra. However, it is beyond the scope of this paper to deal with such a problem more deeply. Also a detailed examination which power law is finally realized is not a main objective of this paper because enough grid-points could not be taken to represent exact power laws in the isotropic wavenumber domain.

Forcing problem must be more realistic to explain $-5 / 3$ power law observed in the atmosphere (e.g., Balsley and Carter, 1982). Nevertheless the decaying problem treated here must be suggestive to understand how (inertio-) gravity waves behave nonlinearly through wavenumber domain.

\section{Basic equations}

Nonlinear shallow water equations on an

\footnotetext{
* Note that the initially given disturbances used here are not vortices but gravity waves since relative vorticity is everywhere zero at an initial moment.
} 
$f$-plane are written as

$$
\begin{aligned}
& \frac{\partial u}{\partial t}-f v+g \frac{\partial h}{\partial x}+u \frac{\partial u}{\partial x}+v \frac{\partial u}{\partial y}=D_{x}, \\
& \frac{\partial v}{\partial t}+f u+g \frac{\partial h}{\partial y}+u \frac{\partial v}{\partial x}+v \frac{\partial v}{\partial y}=D_{y}, \\
& \frac{\partial h}{\partial t}+h\left(\frac{\partial u}{\partial x}+\frac{\partial v}{\partial y}\right)+u \frac{\partial h}{\partial x}+v \frac{\partial h}{\partial y}=0,
\end{aligned}
$$

where $u$ and $v$ are the velocities in the $x$ and $y$-directions, respectively, $h$ the depth of the shallow water, $f$ the Coriolis parameter which is assumed constant, $g$ the gravitational acceleration. $D_{x}$ in (1) and $D_{y}$ in (2) are dissipation terms which will be described later.

Equations (1)-(3) are scaled by introducing dimensionless variables

$$
\begin{array}{ll}
\tilde{x}=x / L, & \tilde{y}=y / L, \\
\tilde{u}=u / \sqrt{H g}, & \tilde{v}=v / \sqrt{H g}, \\
\tilde{h}=h / H, & \tilde{t}=f t, *
\end{array}
$$

where $H$ is the mean depth of the shallow water and $L$ is the characteristic horizontal scale of initially given gravity waves. Substituting (4) into Eqs. (1)-(3), we have a set of dimensionless shallow water equations which are written as

$$
\begin{aligned}
& \frac{\partial u}{\partial t}-v+\varepsilon \frac{\partial h}{\partial x}+\varepsilon\left(u \frac{\partial u}{\partial x}+v \frac{\partial u}{\partial y}\right)=D_{x}, \\
& \left.\frac{\partial v}{\partial t}+u+\varepsilon \frac{\partial h}{\partial y}+\varepsilon\left(u \frac{\partial v}{\partial x}+v \frac{\partial v}{\partial y}\right)=D_{y}, \text { ( } 6\right) \\
& \frac{\partial h}{\partial t}+\varepsilon h\left(\frac{\partial u}{\partial x}+\frac{\partial v}{\partial y}\right)+\varepsilon\left(u \frac{\partial h}{\partial x}+v \frac{\partial h}{\partial y}\right)=0 .
\end{aligned}
$$

Note that, for convenience, circumflex simbols are omitted in Eqs. (5)-(7). Here $\varepsilon$ is a single dimensionless parameter

$$
\varepsilon=R / L,
$$

where $R$ is the Rossby radius of deformation defined as the ratio of the propagation speed of the basic shallow water waves to the Coriolis parameter,

* The time scale used here is somewhat special, which focuses on (inertio-) gravity waves. This time scale is not always suitable for quasi-geostrophic motions (see Pedlosky, 1979).

$$
R=\sqrt{H g} / f .
$$

Rossby radius of deformation is the distance over which the Coriolis force to make the free surface flat is balanced by the gravitational force to deform the surface.

Our problem is to solve Eqs. (5)-(7) numerically for a long period giving a suitable initial condition under the cyclic boundary conditions in both directions in a square domain. Before carrying out numerical time integrations we shall discuss the characteristics of the shallow water equations more in details : one is conservation properties derived from the equations and the other is linear analysis of the equations.

\section{Conservation properties}

It is suggestive to investigate what quantities are conserved if the fluid is assumed to be inviscid. By cross differentiation of Eq. (5) with respect to $x$ and Eq. (6) with respect to $y$ and integration with respect to the twodimensional square domain, we obtain

$$
\frac{\partial}{\partial t} \iint \zeta d x d y=0
$$

where $\zeta$ is the vertical component of the relative vorticity

$$
\zeta=\frac{\partial v}{\partial x}-\frac{\partial u}{\partial y} .
$$

Hence absolute vorticity is conserved in the domain

$$
\frac{\partial}{\partial t} \iint(\zeta+1 / \varepsilon) d x d y=0 .
$$

We also obtain the mass conservation from Eq. (7)

$$
\frac{\partial}{\partial t} \iint h d x d y=0
$$

and the total energy conservation from Eqs. (5)-(7)

$$
\frac{\partial}{\partial t} \iint\left[\frac{u^{2}+v^{2}}{2} h+\frac{h^{2}}{2}\right] d x d y=0 .
$$

The first and the second terms in the parenthesis in (14) are kinetic energy and potential energy per unit area, respectively, which are 
integrated from 0 to $h$. The kinetic energy, $h\left(u^{2}+v^{2}\right) / 2$, can be approximated with good accuracy as $\left(u^{2}+v^{2}\right) / 2$ since $h=1+h^{\prime}\left(h^{\prime} \ll 1\right)$ where $h^{\prime}$ is perturbation depth of the shallow water.

Enstrophy and absolute enstrophy, the square of relative and absolute vorticity, respectively, are not conserved, i.e.,

$$
\begin{aligned}
& -\frac{\partial}{\partial t} \iint \zeta^{2} d x d y \neq 0, \\
& \frac{\partial}{\partial t} \iint(\zeta+1 / \varepsilon)^{2} d x d y \neq 0 .
\end{aligned}
$$

Both potential vorticity and potential enstrophy are not conserved, too, in the two-dimensional square domain :

$$
\left.\begin{array}{c}
\frac{\partial}{\partial t} \iint\left(\frac{\zeta+1 / \varepsilon}{h}\right) d x d y \neq 0, \\
\frac{\partial}{\partial t} \iint\left(\frac{\zeta+1 / \varepsilon}{h}\right)^{2} d x d y \neq 0,
\end{array}\right\}
$$

because the fluid is divergent. Here note that, of course, the potential vorticity and potential enstrophy are conserved on a fluid parcel:

$$
\frac{d}{d t}\left(\frac{\zeta+1 / \varepsilon}{h}\right)=0, \quad \frac{d}{d t}\left(\frac{\zeta+1 / \varepsilon}{h}\right)^{2}=0 .
$$

As mentioned in the previous chapter, breakdown of absolute and potential enstrophy conservations suggests that turbulent upscale energy transfer is not always active in the shallow water gravity wave regime.

\section{Linearized system of shallow water equations}

An inviscid linearized system of the dimensionless shallow water equations is

$$
\begin{aligned}
& \frac{\partial u}{\partial t}-v+\varepsilon \frac{\partial h}{\partial x}=0, \\
& \frac{\partial v}{\partial t}+u+\varepsilon \frac{\partial h}{\partial y}=0, \\
& \frac{\partial h}{\partial t}+\varepsilon\left(\frac{\partial u}{\partial x}+\frac{\partial v}{\partial y}\right)=0 .
\end{aligned}
$$

Assuming that $u, v$ and $h$ are proportional to $\exp (i k x+i l y-i \omega t)$ and substituting them into Eqs. (18), (19) and (20), we have the dispersion relations

$$
\begin{aligned}
& \omega_{R}=0, \\
& \omega_{G}= \pm \sqrt{1+\varepsilon^{2}\left(k^{2}+l^{2}\right) .}
\end{aligned}
$$

Here (21) expresses the dispersion relation of geostrophic motions (or degenerated Rossby waves), which is independent of wavenumbers, and (22) shows the dispersion relations of inertio-gravity waves propagating to the opposite directions. When $\varepsilon \rightarrow 0, \omega_{G}$ tends to inertial frequency.

\section{Time integration of the shallow water equations}

Pseudo-spectral method on a two-dimensional complex domain was used to integrate the shallow water equations (5)-(7) in order to suppress aliasing errors. Fourier transformation of Eqs. (5)-(7) is

$$
\begin{aligned}
& \frac{\partial \hat{u}}{\partial t}-\hat{v}+i k \varepsilon \hat{h}+\varepsilon\left(\widehat{u} \frac{\partial u}{\partial x}+\widehat{v} \frac{\partial u}{\partial y}\right)=\hat{D}_{x}, \\
& \frac{\partial \hat{v}}{\partial t}+\hat{u}+i l \varepsilon \hat{h}+\varepsilon\left(\widehat{u \frac{\partial v}{\partial x}}+\widehat{v \frac{\partial v}{\partial y}}\right)=\hat{D}_{y}, \\
& \frac{\partial \hat{h}}{\partial t}+\varepsilon\left(\widehat{h \frac{\partial u}{\partial x}}+h \widehat{\frac{\partial v}{\partial y}}\right)+\varepsilon\left(\widehat{u \frac{\partial h}{\partial x}}+\widehat{v \frac{\partial h}{\partial y}}\right)=0,
\end{aligned}
$$

where the symbol $\wedge$ denotes Fourier transform and the quantities with the symbol depend on $k, l$ and $t$.

In order to suppress the truncation errors, strong dissipation terms were introduced particularly in the higher wavenumber domain than $K_{c}$, which are expressed as

$$
\begin{aligned}
& \hat{D}_{x}=\left\{\begin{array}{ll}
A \hat{u} & \cdots \cdots K<K_{c}, \\
{\left[A+\bar{\nu}\left(K-K_{c}\right)^{4}\right] \hat{u} \cdots \cdots K \geqq K_{c},}
\end{array},\right. \\
& \hat{D}_{y}=\left\{\begin{array}{l}
A \hat{v} \\
{\left[A+\bar{\nu}\left(K-K_{c}\right)^{4}\right] \hat{v} \cdots \cdots K K K_{c},}
\end{array},\right.
\end{aligned}
$$

where $K\left(=\sqrt{k^{2}+l^{2}}\right)$ is the scalar total wavenumber. $A$ is the coefficient of very weak Rayleigh damping and $\bar{\nu}$ the dimensionless viscosity associated with biharmonic friction.

The transform method developed by Orszag (1971) was used to calculate the nonlinear terms. For example, in order to calculate $u(\partial u / \partial x)$ in the physical space, $\partial u / \partial x$ is once expressed in the spectral space applying high- 
speed FFT and then the quantity is transformed to the physical space. After calculating products of $u$ and $\partial u / \partial x$ at each gridpoint, Fourier transformation from the physical space to the spectral space is performed for the next step integration. Such a process is applied to all nonlinear terms in Eqs. (23)(25) at each time step. The pseudo-spectral method is a powerful tool for long-period time integrations of equations with cyclic boundary conditions because approximation of derivatives is much better compared with the grid methods. As an initial condition, spectral values of $\hat{h}$ with random amplitudes and phases were specified at grid-points within a circular belt in the scalar wavenumber space, $K_{i}<K$ $<K_{0}$.

Dimensionless form of the vorticity equation derived from Eqs. (5) and (6) is written as

$$
\begin{aligned}
& \frac{\partial \zeta}{\partial t}+(1+\varepsilon \zeta)\left(\frac{\partial u}{\partial x}+\frac{\partial v}{\partial y}\right)+\varepsilon\left(u \frac{\partial \zeta}{\partial x}+v \frac{\partial \zeta}{\partial y}\right) \\
& =0,
\end{aligned}
$$

if dissipation terms, $D_{x}$ and $D_{y}$, are omitted. Equation of the perturbed depth is derived from Eq. (7)

$$
\begin{aligned}
& \frac{\partial h^{\prime}}{\partial t}+\varepsilon\left(1+h^{\prime}\right)\left(\frac{\partial u}{\partial x}+\frac{\partial v}{\partial y}\right)+\varepsilon\left(u \frac{\partial h^{\prime}}{\partial x}+v \frac{\partial h^{\prime}}{\partial y}\right) \\
& \quad=0 .
\end{aligned}
$$

Eq. (28) becomes exactly the same form as Eq. (29) when $\varepsilon=1$.

Potential vorticity equation shown in (17) leads to

$$
\zeta+1 / \varepsilon=\frac{1}{\varepsilon} \cdot \frac{1+h^{\prime}}{1+h_{0}^{\prime}},
$$

when $\zeta=0$ and $h^{\prime}=h_{0}^{\prime}$ at an initial moment. However, (30) breaks for shorter wavelength domain than the initially given gravity waves due to strong viscous effect. For longer wavelength domain than the input gravity waves where the fluid is inviscid and is initially undisturbed, (30) must be changed as

$$
\zeta+1 / \varepsilon=\frac{1}{\varepsilon}\left(1+h^{\prime}\right)
$$

by putting $h_{0}^{\prime}=0$ in (30). This means that the absolute vorticity is proportional to the total depth. The relative vorticity is also proportional to the perturbed depth. When $\varepsilon=1$, both fields coincide perfectly.

The kinetic energy and the potential energy in the wavenumber space are given, respectively, by

$$
\begin{aligned}
& E_{K}(k, l)=0.5 \times\left[\hat{u}(k, l) \hat{u}^{*}(k, l)\right. \\
& \left.\quad+\hat{v}(k, l) \hat{v}^{*}(k, l)\right], \\
& E_{P}(k, l)=0.5 \times \hat{h}(k, l) \hat{h}^{*}(k, l),
\end{aligned}
$$

where asterisk denotes the complex conjugate. The total energy is also devided into two parts (cf. Kasahara, 1977, 1982): one is associated with geostrophic motions

$$
E_{R}(k, l)=0.5 \times W_{R}(k, l) W_{R}^{*}(k, l),
$$

and the other is associated with (inertio-) gravity waves

$$
\begin{aligned}
& E_{G}(k, l)=0.5 \times\left[W_{G_{+}}(k, l) W_{G_{+}}^{*}(k, l)\right. \\
& \left.\quad+W_{G_{-}}(k, l) W_{G_{-}}^{*}(k, l)\right],
\end{aligned}
$$

where $W_{R}(k, l), W_{G_{+}}(k, l)$ and $W_{G_{-}}(k, l)$ are given by

$$
\begin{aligned}
& W_{R}(k, l)=\hat{u}(k, l) U_{R}^{*}(k, l) \\
& \quad+\hat{v}(k, l) V_{R}^{*}(k, l)+\hat{h}(k, l) H_{R}^{*}(k, l), \\
& W_{G_{+}}(k, l)=\hat{u}(k, l) U_{G_{+}}^{*}(k, l) \\
& \quad+\hat{v}(k, l) V_{G_{+}}^{*}(k, l)+\hat{h}(k, l) H_{G_{+}}^{*}(k, l), \\
& W_{G_{-}}(k, l)=\hat{u}(k, l) U_{G_{-}}^{*}(k, l) \\
& \quad+\hat{v}(k, l) V_{G_{-}}^{*}(k, l)+\hat{h}(k, l) H_{G_{-}}^{*}(k, l) .
\end{aligned}
$$

Here $U_{\alpha}(k, l), V_{\alpha}(k, l)$ and $H_{\alpha}(k, l)$ for $\alpha=R$, $G_{+}, G_{-}$are the normalized amplitudes of velocity and depth for geostrophic motions and gravity waves and can be obtained from the eigen values of inviscid and linearized equations (5)-(7) :

$$
\begin{aligned}
& {\left[\begin{array}{l}
U_{R}(k, l) \\
V_{R}(k, l) \\
H_{R}(k, l)
\end{array}\right]=\frac{1}{\sigma}\left[\begin{array}{c}
-i \varepsilon l \\
i \varepsilon k \\
1
\end{array}\right],} \\
& {\left[\begin{array}{l}
U_{G_{+}}(k, l) \\
V_{G_{+}}(k, l) \\
H_{G_{+}}(k, l)
\end{array}\right]=\frac{1}{\sqrt{2\left(k^{2}+l^{2}\right)}}\left[\begin{array}{c}
k+i l / \sigma \\
l-i k / \sigma \\
\varepsilon\left(k^{2}+l^{2}\right) / \sigma
\end{array}\right],}
\end{aligned}
$$




$$
\left[\begin{array}{l}
U_{G_{-}}(k, l) \\
V_{G_{-}}(k, l) \\
H_{G_{-}}(k, l)
\end{array}\right]=\frac{1}{\sqrt{2\left(k^{2}+l^{2}\right)}}\left[\begin{array}{c}
-k+i l / \sigma \\
-l-i k / \sigma \\
\varepsilon\left(k^{2}+l^{2}\right) / \sigma
\end{array}\right],
$$

where $\sigma \equiv \sqrt{1+\varepsilon^{2}\left(\overline{k^{2}}+l^{2}\right)}$. Note that the normalization relations

$$
\begin{aligned}
& U_{\alpha}(k, l) U_{\alpha}^{*}(k, l)+V_{\alpha}(k, l) V_{\alpha}^{*}(k, l) \\
& \quad+H_{\alpha}(k, l) H_{\alpha}^{*}(k, l)=1
\end{aligned}
$$

are satisfied for three modes of $\alpha=R, G_{+}, G_{-}$.

When $\varepsilon \rightarrow 0$, Eqs. (23)-(25) become

$$
\begin{aligned}
& \frac{\partial \hat{u}}{\partial t}-\hat{v}=0, \\
& \frac{\partial \hat{v}}{\partial t}+\hat{u}=0, \\
& \frac{\partial \hat{h}}{\partial t}=0,
\end{aligned}
$$

when $\hat{D}_{x}=\hat{D}_{y}=0$. This case corresponds to inertial oscillations of velocity fields keeping a constant depth. Thus we have from (36)

$$
\left[\begin{array}{l}
U_{R} \\
V_{R} \\
H_{R}
\end{array}\right]=\left[\begin{array}{l}
0 \\
0 \\
1
\end{array}\right],
$$

so that the geostrophic motions disappear.

\section{Results}

Time integrations were carried out only for the case of $\varepsilon=1$ where Rossby radius of de- formation is identical to the characteristic scale of initial disturbances. The parameters used for the calculation are as follows: number of grid-point $N=32$, time increment $\Delta t=$ 0.003, Rayleigh damping coefficient $A=10^{4}$, biharmonic viscosity $\bar{\nu}=4.3 \times 10^{-7}$, smallest scalar wavenumber for viscous dissipation $K_{c}$ $=5.5$. The scalar wavenumber domain for the initial disturbances ranges from $K=5$ $\left(\equiv K_{i}\right)$ to $7\left(\equiv K_{0}\right)$. The cyclic scale unit is about $6 R$ in this case. This scale is considered to be so large that the cyclic conditions might not deform the fields artifitially. Initial condition for depth perturbations in the spectral space is produced by the equation

$$
\hat{h}^{\prime}=\gamma \hat{h}_{r} e^{2 \pi i \theta_{r}},
$$

where $\hat{h}_{r}$ and $\theta_{r}$ are the random numbers between 0 and 1 reproduced by the "RANF" subroutine of NCAR CRAY-1, $\gamma$ the dimensionless maximum amplitude of depth perturbations, which is chosen here to be 0.005 . No perturbations are given for $\hat{u}$ and $\hat{v}$.

Figures $1(\mathrm{a})-(\mathrm{h})$ demonstrate the evolution of the depth in the physical space at every 10000 time step. The initial disturbances of the depth are characterized by the wavenumber centered around $K=6$. At 10000th time step the input disturbances are still predominant. However, it should be noted that the disturbances have two distinguished features: firstly degree of randomness of the disturbances tend to decrease with time, so that the disturbances seem to be distributed more sys-

\section{Explanation of Figures 1 and 2}

Fig. 1 Time evolution of the total depth $(h)$ when $\varepsilon=1$. Dimensionless times are shown in the parentheses. Dimensionless contour intervals are also shown at each time step. Domains where $h$ is less than unity are shaded especially at the last two time steps.
(a) Initial $(t=0) 0.6 \times 10^{-2}$
(c) 20000th time step $(t=60) \quad 0.5 \times 10^{-3}$
(b) 10000th time step $(t=30) \quad 0.6 \times 10^{-3}$
(e) 40000th time step $(t=120) 0.2 \times 10^{-2}$
(d) 30000th time step $(t=90) \quad 0.3 \times 10^{-3}$
(f) 50000 th time step $(t=150) 0.2 \times 10^{-3}$
(g) 60000 th time step $(t=180) 0.2 \times 10^{-3}$
(h) 70000 th time step $(t=210) 0.1 \times 10^{-3}$

Fig. 2 Time evolution of the relative vorticity $(\zeta)$ when $\varepsilon=1$. Dimensionless times and contour intervals are shown at each time step. Dashed-line contours show negative values of $\zeta$. Domains. where $\zeta$ is negative are shaded especially at the last two time steps.
(a) Initial $(t=0)$
(c) 20000th time step $(t=60) \quad 0.5 \times 10^{-3}$
(b) 10000th time step $(t=30) \quad 0.1 \times 10^{-2}$
(e) 40000th time step $(t=120) 0.2 \times 10^{-3}$
(d) 30000th time step $(t=90) \quad 0.3 \times 10^{-3}$
(g) 60000 th time step $(t=180) 0.2 \times 10^{-3}$
(f) 50000 th time step $(t=150) 0.2 \times 10^{-3}$
(h) 70000 th time step $(t=210) 0.1 \times 10^{-3}$ 

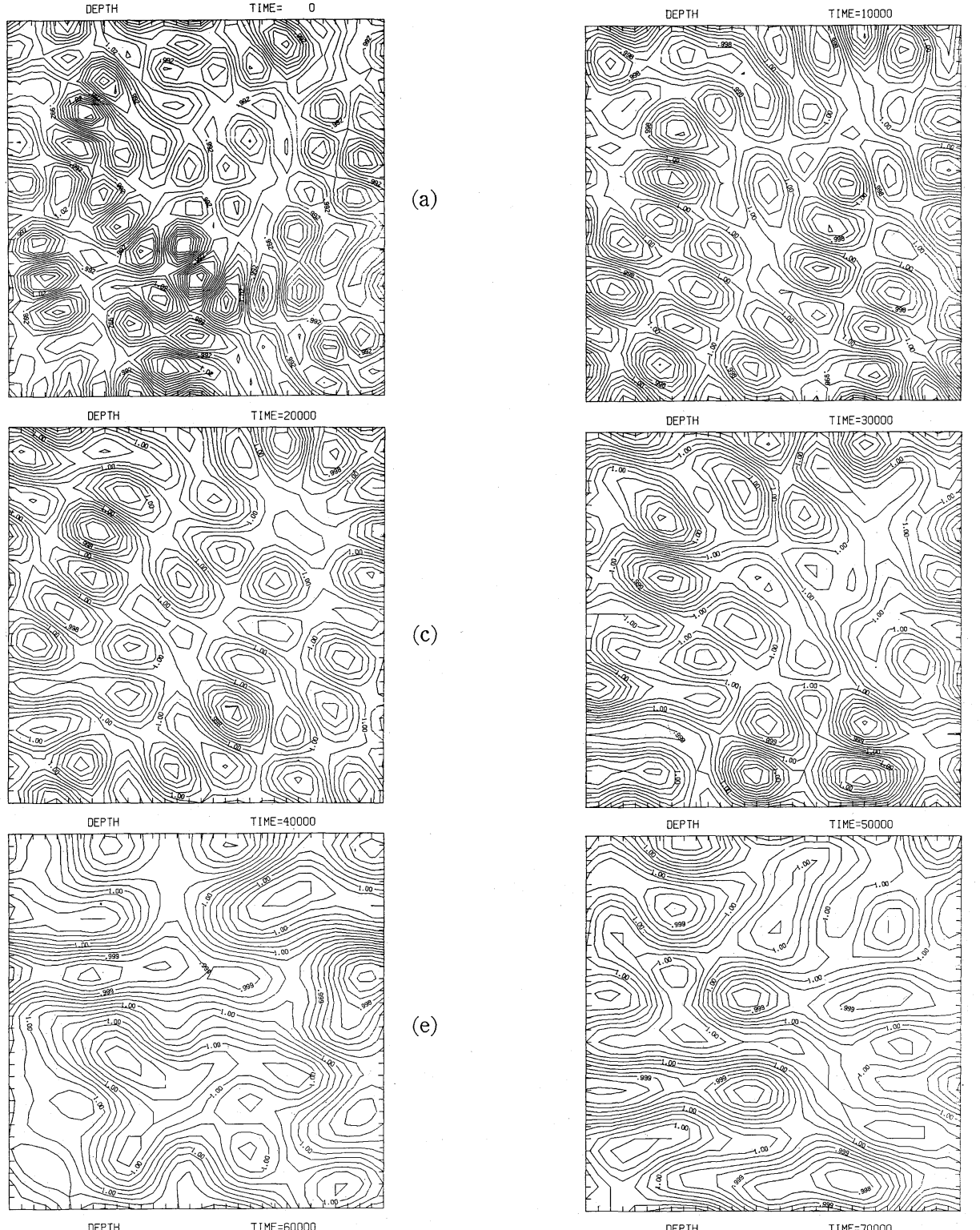

(b)
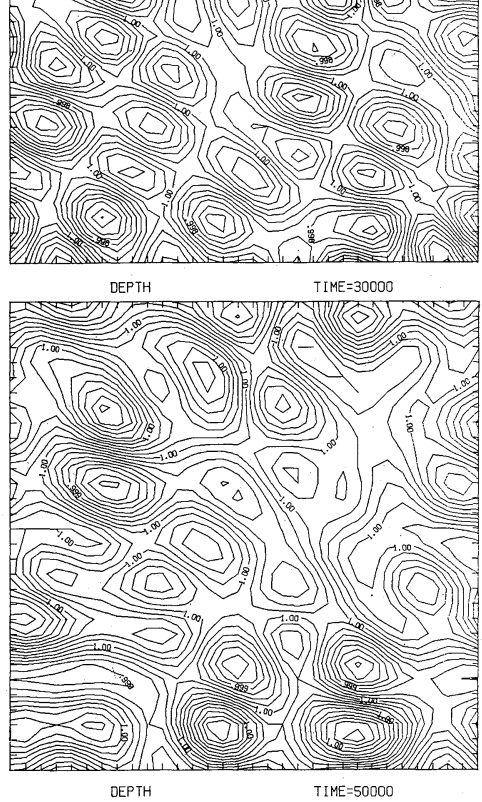

(d)
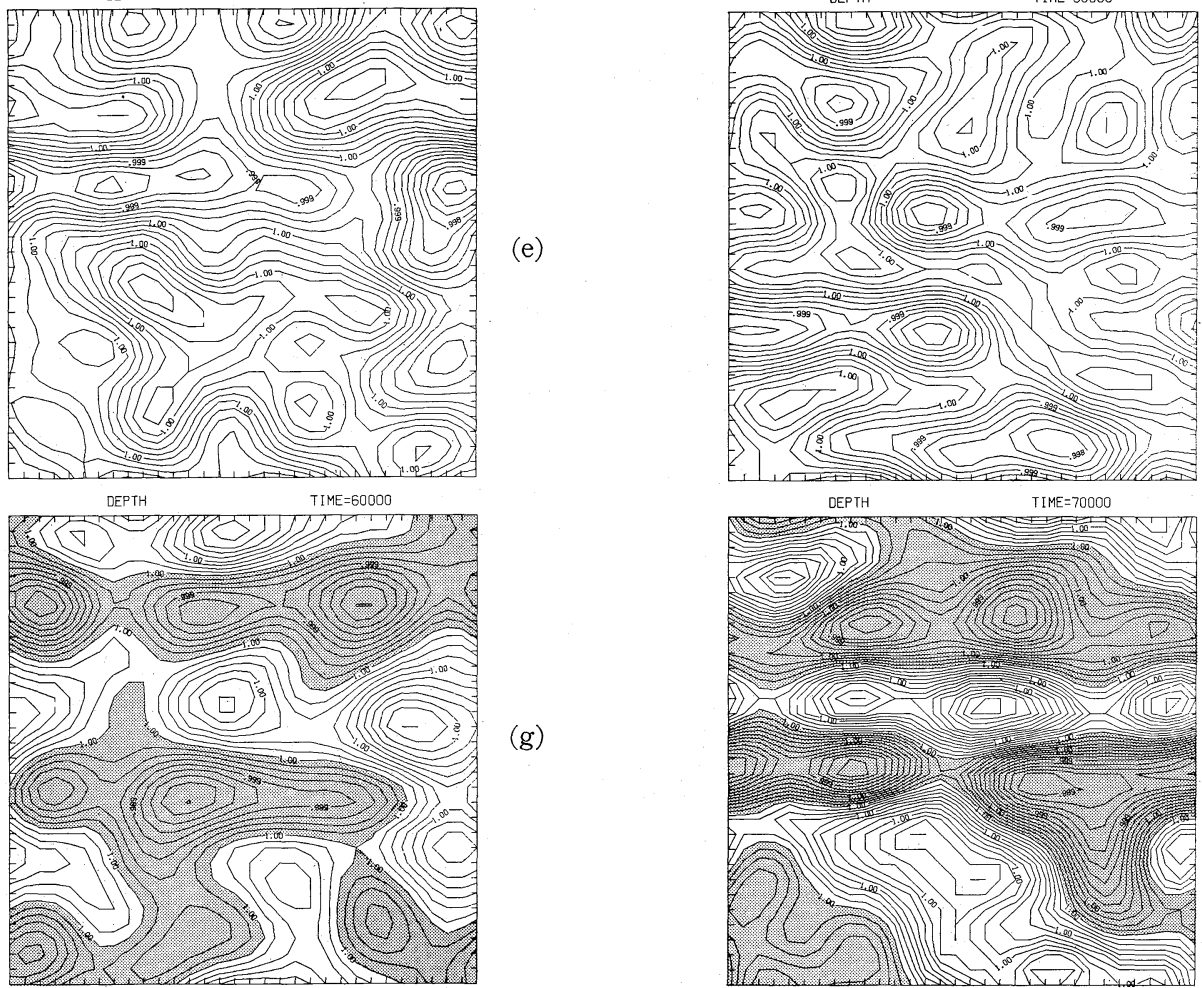

Fig. 1 

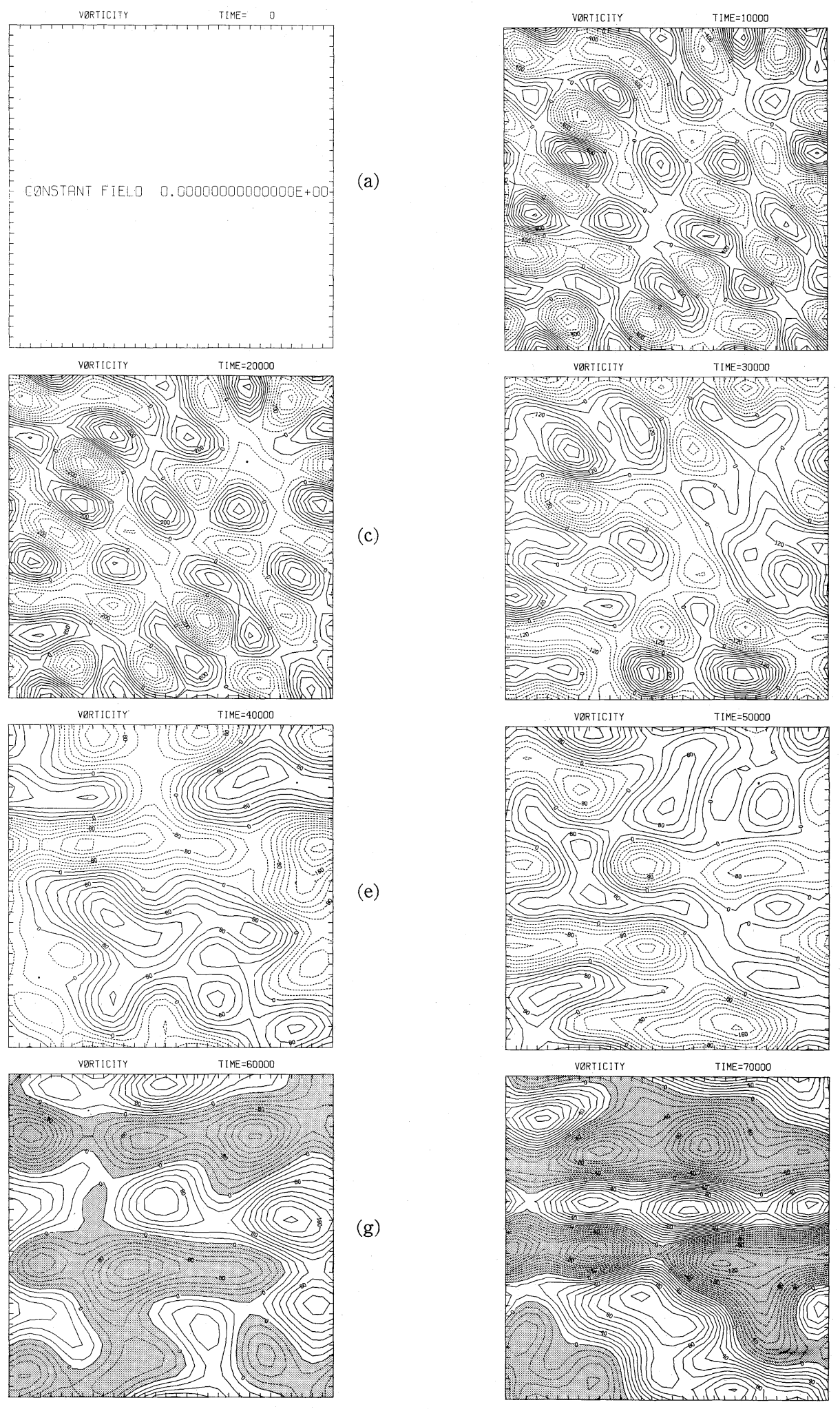

(b)

(c)

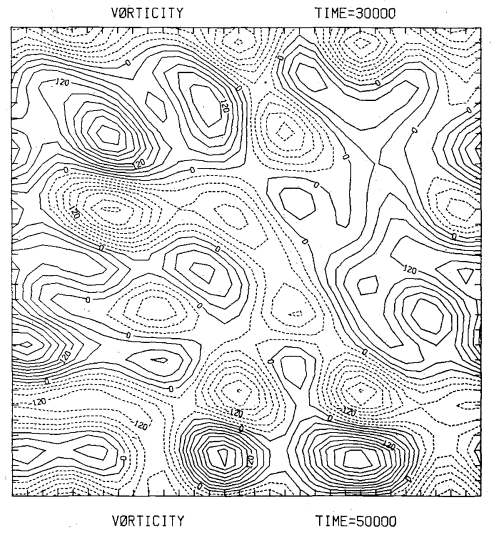

(e)
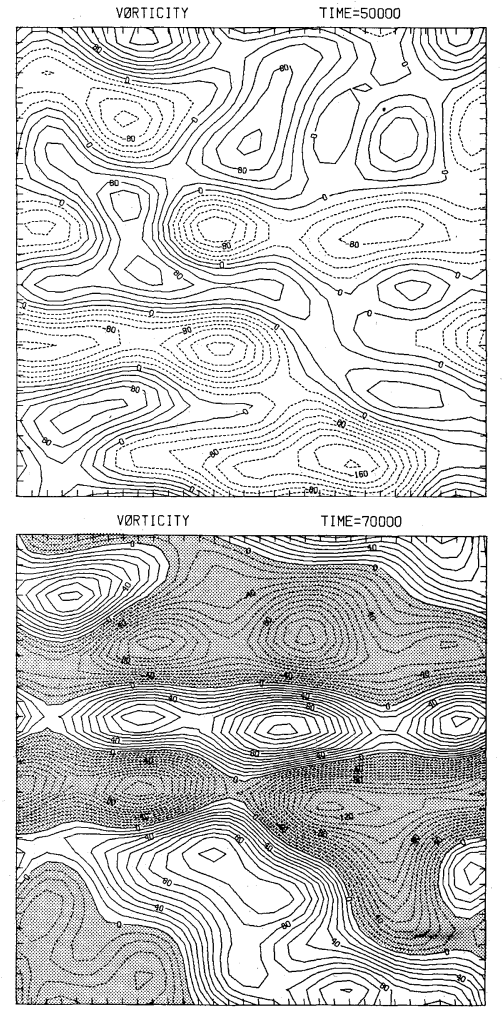

Fig. 2 
tematically toward a specific direction than the initial disturbances, secondly predominant scale of the disturbances shift slightly to larger scale. The first feature is caused by the selective nonlinear interactions among several wavenumber modes. Eventually only a small number of modes can survive. The second feature is rather clear. Since higher wave- number part of the initial disturbances is dissipated more rapidly than lower one, wavenumber 5 becomes predominant. At 20000th time step the initial disturbances are still surviving clearly lined up to a specific direction. Larger eddies are weakly found, too. Through 30000 to 50000th time steps the large eddies become gradually remarkable as the

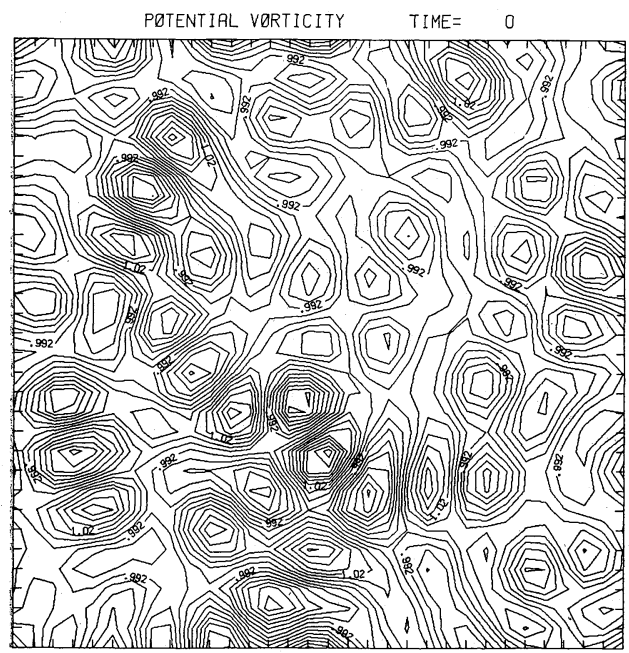

(a)

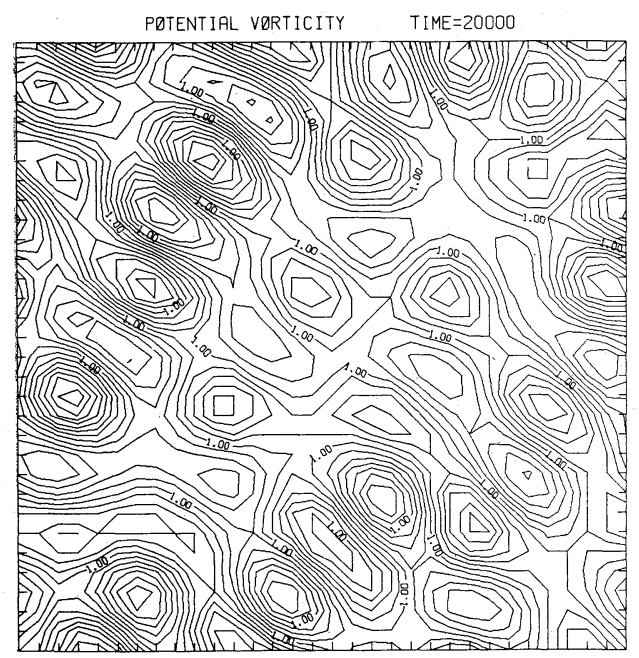

(c)

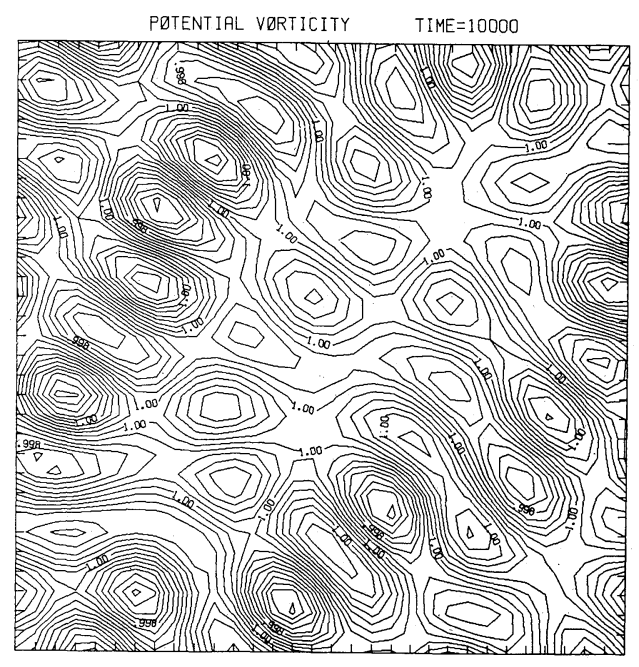

(b)

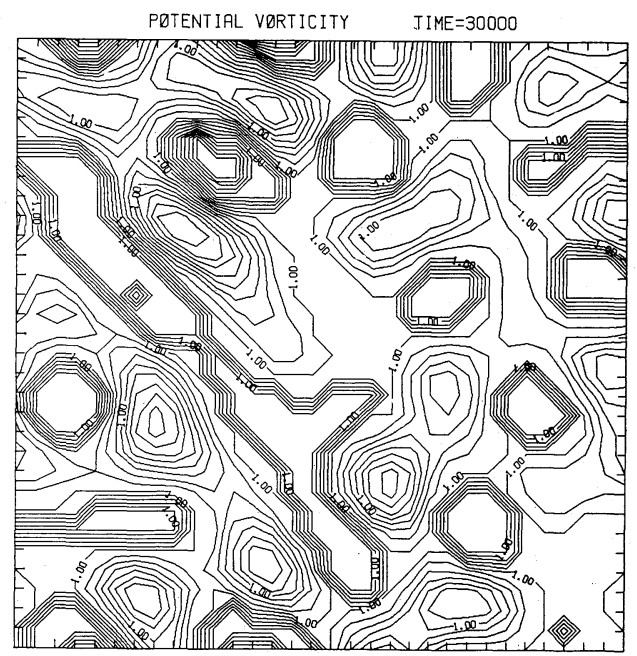

(d)

Fig. 3 Time evolution of the potential vorticity $(q)$ when $\varepsilon=1$. Dimensionless times and contour intervals are shown at each time step.

(a) Initial $(t=0) \quad 0.6 \times 10^{-2}$

(c) 20000th time step $(t=60) \quad 0.1 \times 10^{-3}$

(b) 10000th time step $(t=30) 0.5 \times 10^{-3}$

(d) 30000 th time step $(t=90) 0.2 \times 10^{-4}$ 
initial disturbances have been dissipated to become insignificant in their magnitude. Such elongated large eddies seem to possess intermediate features between nonlinear turbulent eddies and linear (inertio-) gravity waves. The wave-like structure becomes very remarkable at 70000 th time step as shown in Fig. 1(h).

Figures 2(a)-(h) show the time evolution of relative vorticity, $\zeta$. No relative vorticity is found initially because no velocity field is enforced. At 10000th time step the vorticity field tends to coincide with depth field though some differences between them are still found. As found in the evolution of the depth field, systematic alignment of the vorticity field produced through selective nonlinear inter-

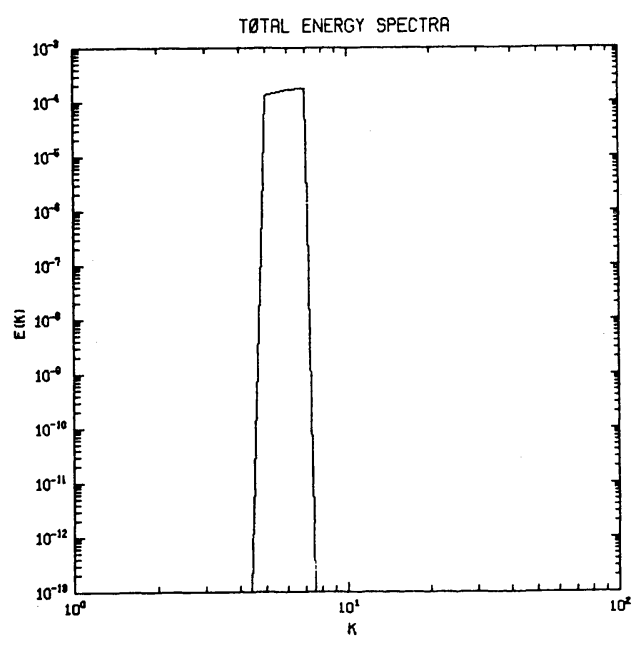

(a)

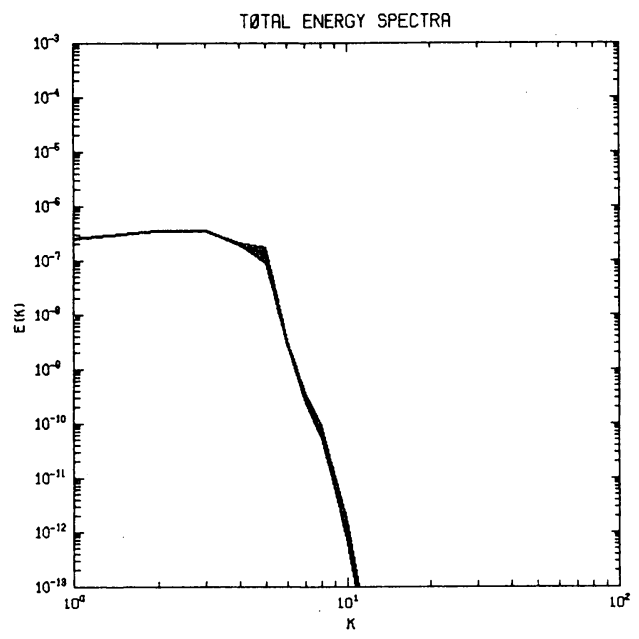

(c)

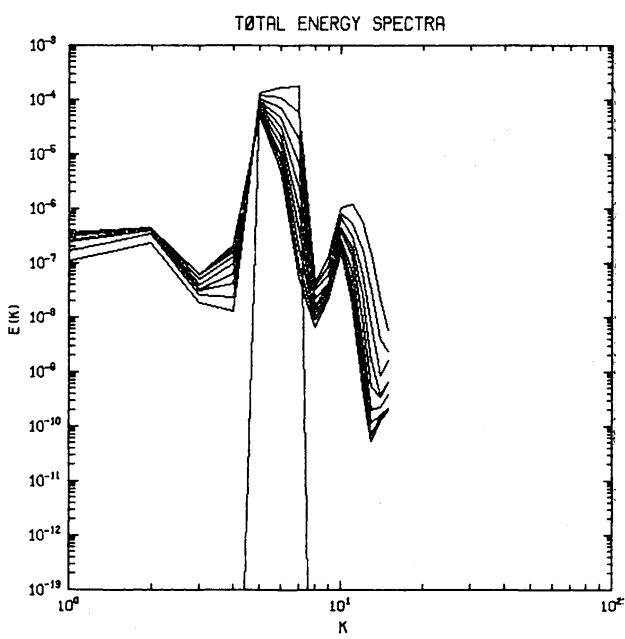

(b)

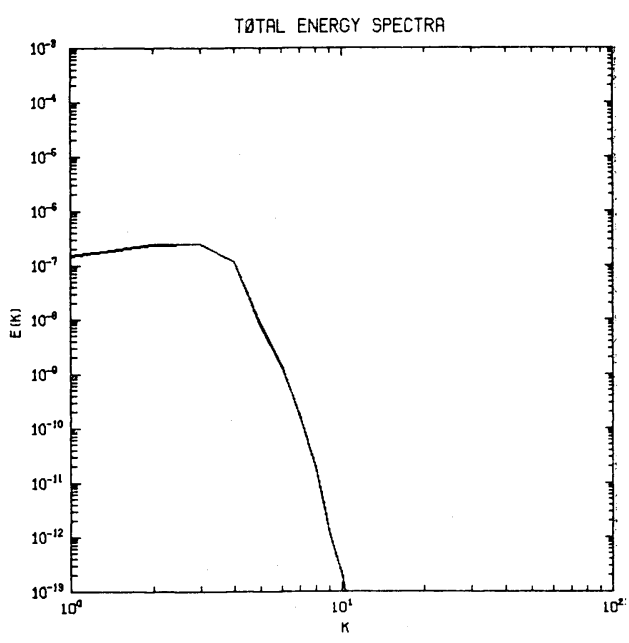

(d)

Fig. 4 Time evolution of total energy spectra when $\varepsilon=1$. The figures, except (a), show the sunerposed spectra at every 500 time steps (1.5 in dimensionless unit). Dimensionless times are shown in the parentheses.
(a) Initial $(t=0)$
(b) $0-4500$ th time step $(0 \leqq t \leqq 13.5)$
(c) $45000-49500$ th time step $(135 \leqq t \leqq 148.5)$
(d) 75000-79500th time step $(225 \leqq t \leqq 238.5)$ 
actions among waves is well recognized. Such a systematic alignment of the vorticity field is still found at 20000th time step. Coincidence between depth field and vorticity field is completed after this time step (see Figs. 1(g), (h) and Figs. 2(g), (h)). A possible reason was described in the previous chapter especially in (31) which is perfectly satisfied quantitatively in the late stages of evolution.

Potential vorticity, say $q$, can be expanded

$$
q=\frac{\zeta+1 / \varepsilon}{1+h^{\prime}} \cong \frac{1}{\varepsilon}+\left(\zeta-\frac{h^{\prime}}{\varepsilon}\right)+\cdots,
$$

since maximum amplitudes of $h^{\prime}$ and $\zeta$ are sufficiently smaller than unity. At an initial moment $q$ is approximately expressed as

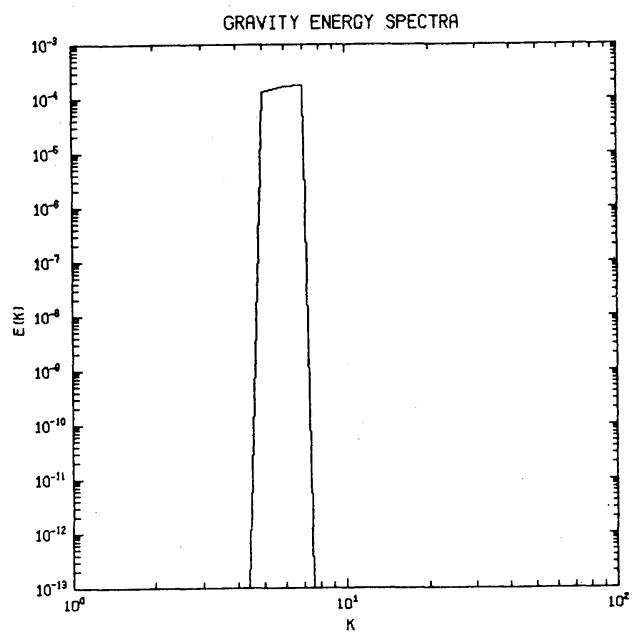

(a)

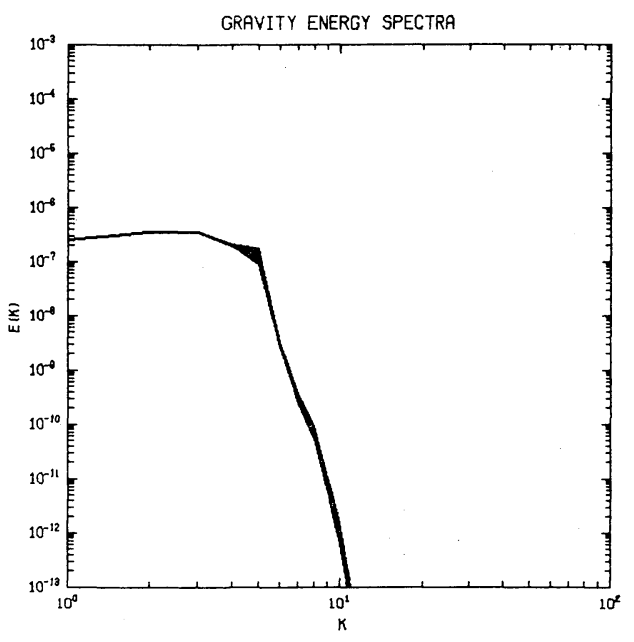

(c)

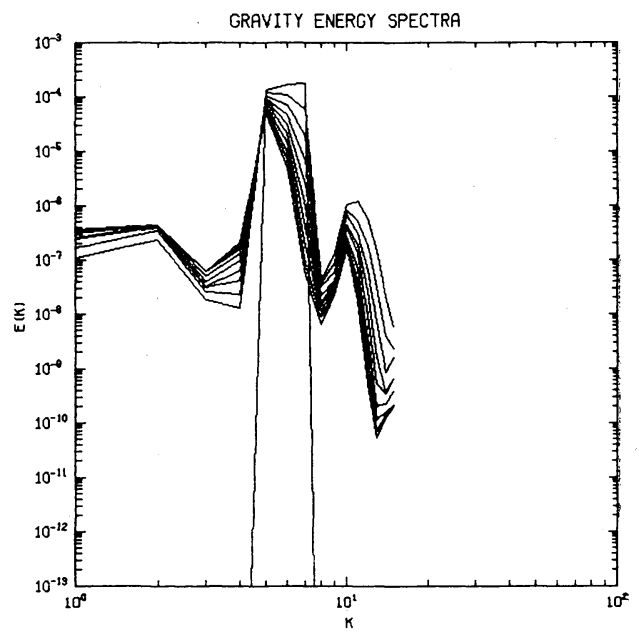

(b)

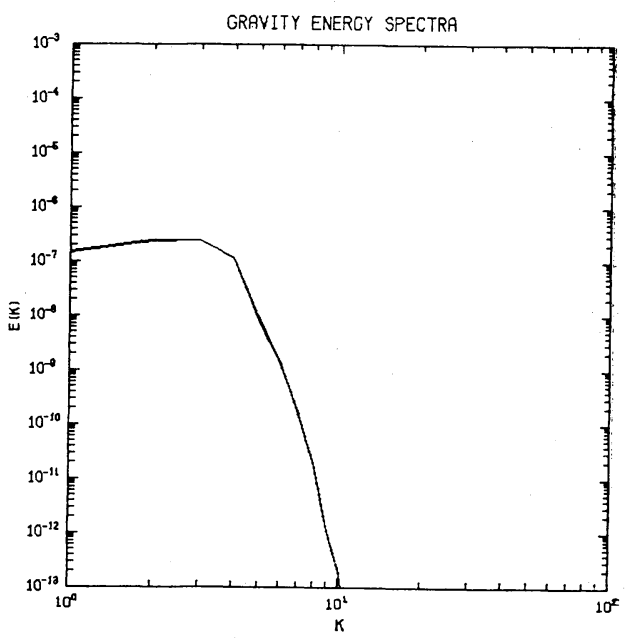

(d)

Fig. 5 Same as Fig. 4 but for gravity-wave energy spectra.
(a) Initial $(t=0)$
(b) $0-4500$ th time step $(0 \leqq t \leqq 13.5)$
(c) $45000-49500$ th time step $(135 \leqq t \leqq 148.5)$
(d) 75000-79500th time step $(225 \leqq t \leqq 238.5$ ) 


$$
q \cong \frac{1}{\varepsilon}\left(1-h^{\prime}\right),
$$

which is shown in Fig. 3(a). As the vorticity field grows, the potential vorticity field must be expressed by (45), which are shown in Figs. 3(b) and (c) if one inspects the figures in detail. As was mentioned already, the

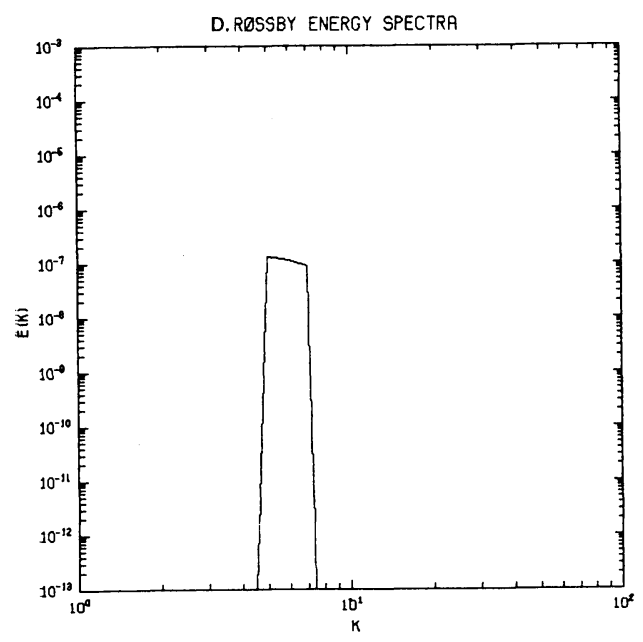

(a)

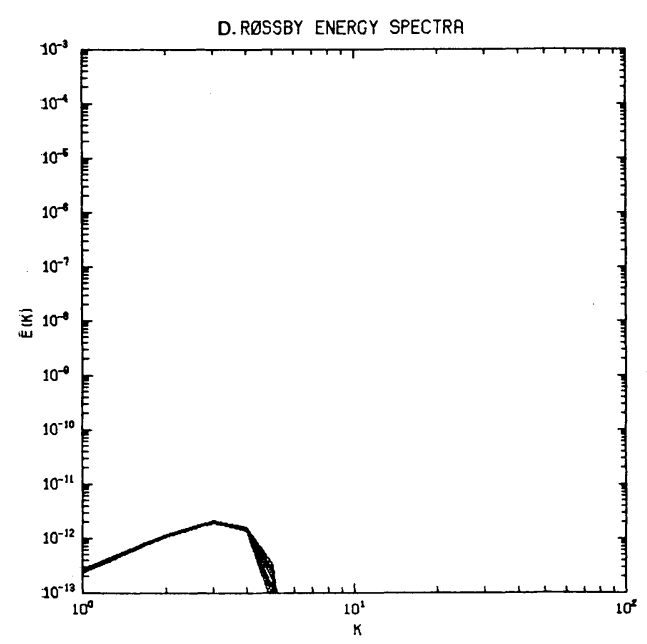

(c) relative vorticity $(\zeta)$ tends to the perturbed depth $\left(h^{\prime}\right)$ and consequently the potential vorticity tends to unity (see Fig. 3(d)). This fact states that the wave-like patterns finally produced are (inertio-) gravity waves.

The initial shape of the total energy spectrum is shown in Fig. 4(a). Figs. 4(b), (c) and (d) show the superposed total energy spectra

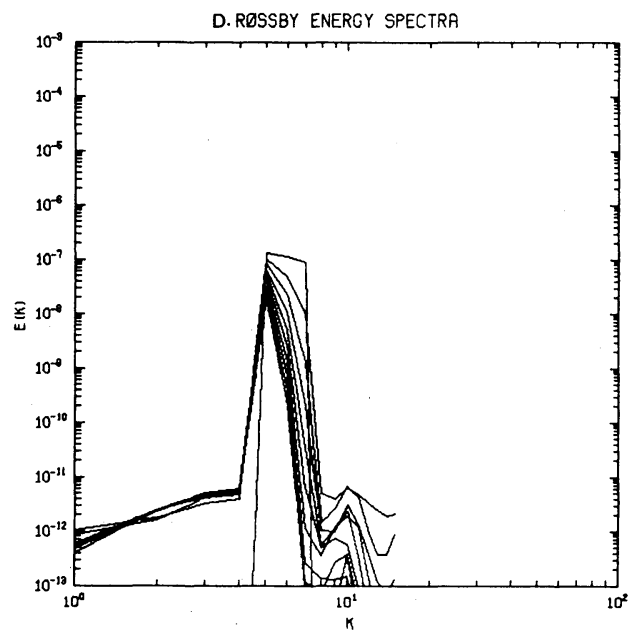

(b)

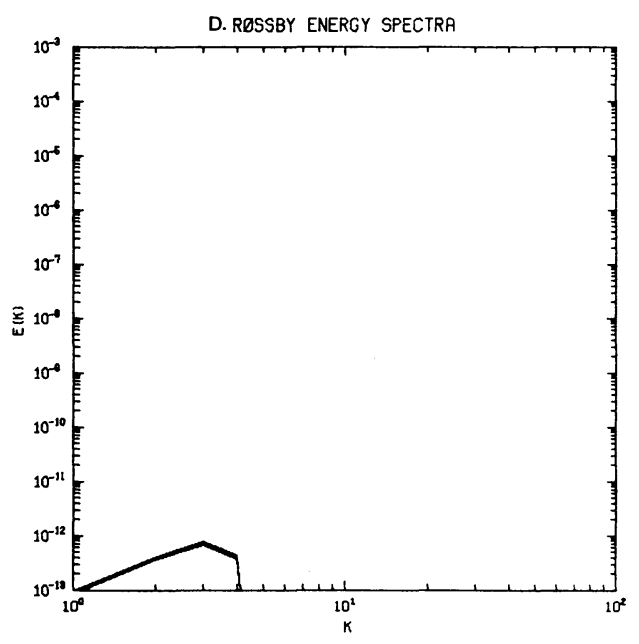

(d)

Fig. 6 Same as Fig. 4 but for geostrophic-motion energy spectra.
(a) Initial $(t=0)$
(c) $45000-49500$ th time step $(135 \leqq t \leqq 148.5)$
(b) $0-4500$ th time step $(0 \leqq t \leqq 13.5)$
(d) 75000-79500th time step $(225 \leqq t \leqq 238.5)$ 
at every 500 time steps from 0 to 4500 th, 45000 th to 49500 th, and 75000 th to 79500 th time steps, respectively. Each figure includes ten spectra. Time evolution of the upscale energy transfer is found early stages together with the generation of biharmonics and their subsequent rapid dissipation (see Fig. 4(b)). In Fig. 4(c) and particularly in Fig. 4(d), the

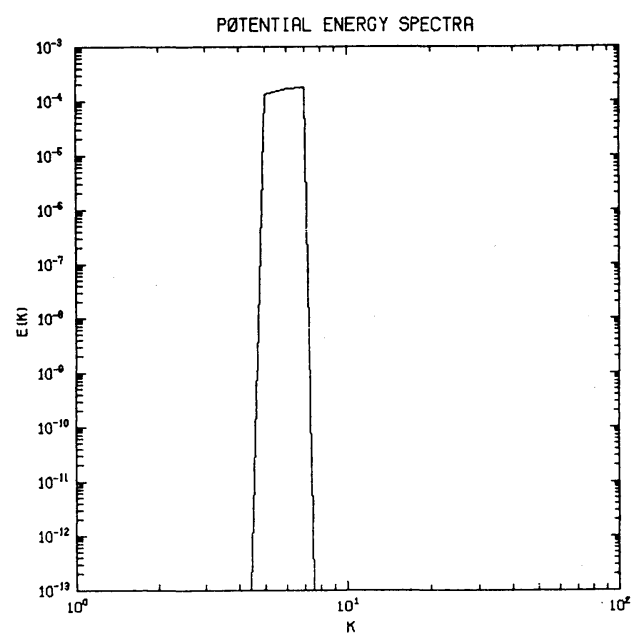

(a)

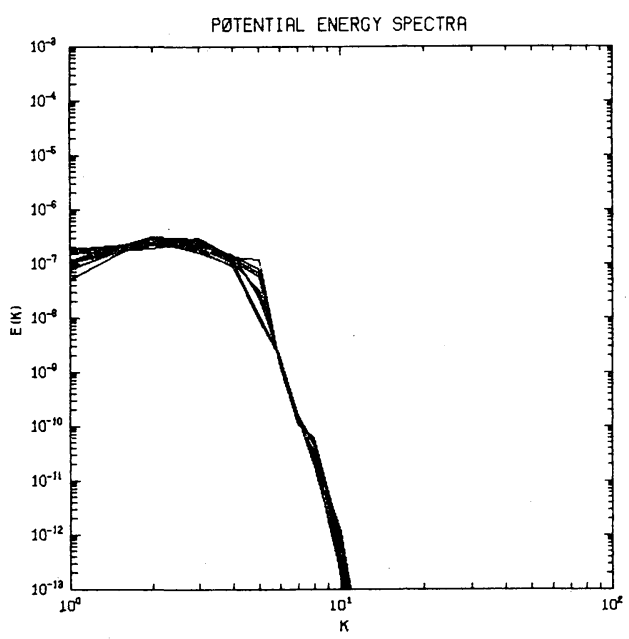

(c) total energy spectra stop changing and seem to reach an equilibrium state. Here it should be reminded that major part of the upscale energy transfer is completed rapidly in the early stages as is demonstrated in Fig. 4(b). Remember that the nonlinear interactions among wavenumbers can fully occur when dimensionless time exceeds unity. Then 500th

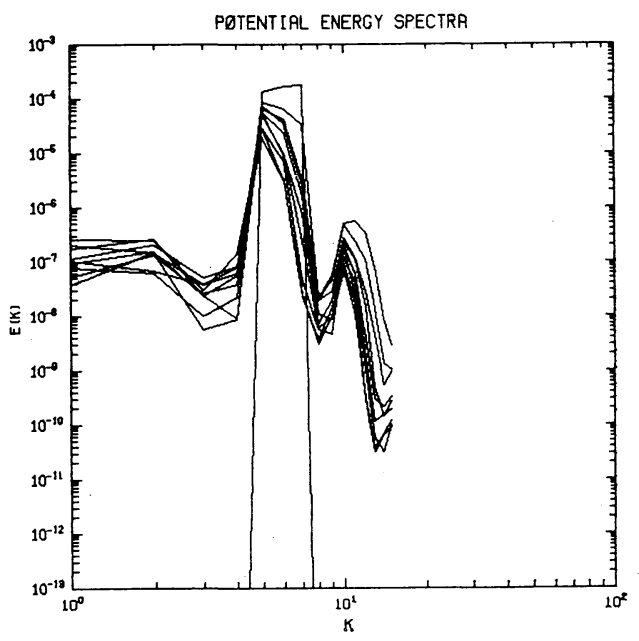

(b)

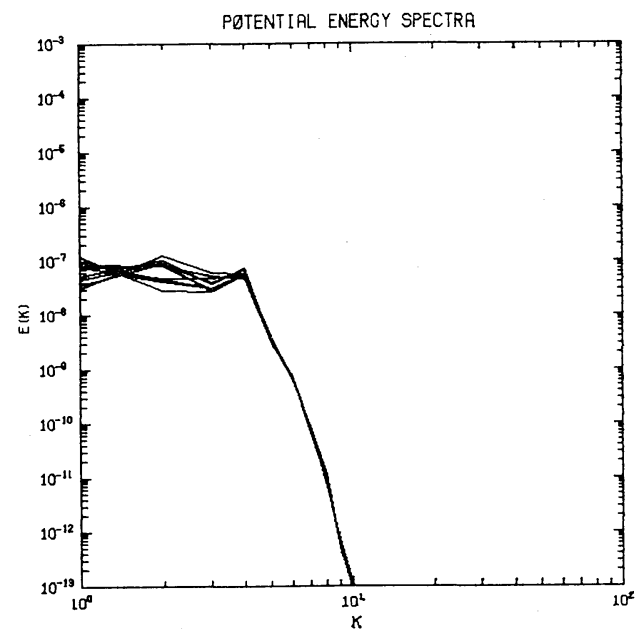

(d)

Fig. 7 Same as Fig. 4 but for potential energy spectra.
(a) Initial $(t=0)$
(b) $0-4500$ th time step $(0 \leqq t \leqq 13.5)$
(c) $45000-49500$ th time step $(135 \leqq t \leqq 148.5)$
(d) $75000-79500$ th time step $(225 \leqq t \leqq 238.5)$ 
time step, which corresponds to 1.5 in dimensionless time, must be sufficient for the fully developed nonlinear interactions.

At subsequent stages nonlinear fine adjustment continues and an equilibrium will be approached by transferring small amount of energy among wavenumbers. A spectral peak appear at $K=3\left(\equiv K_{p}\right)$, though not very sharp,

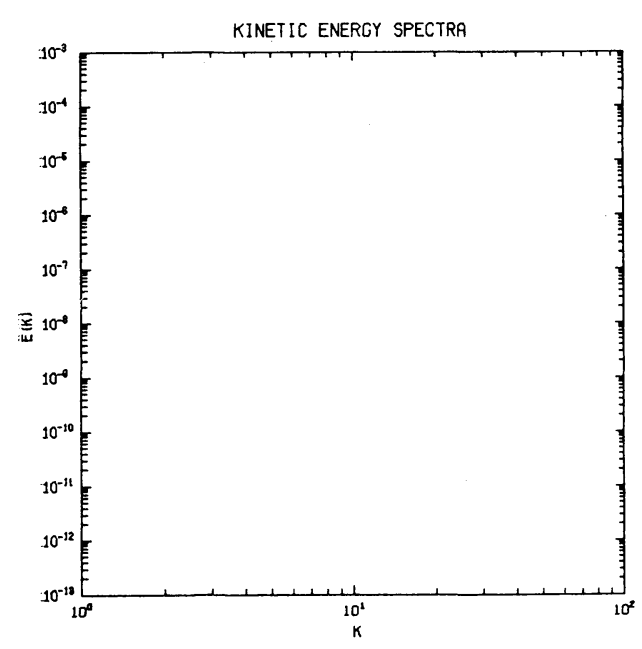

(a)

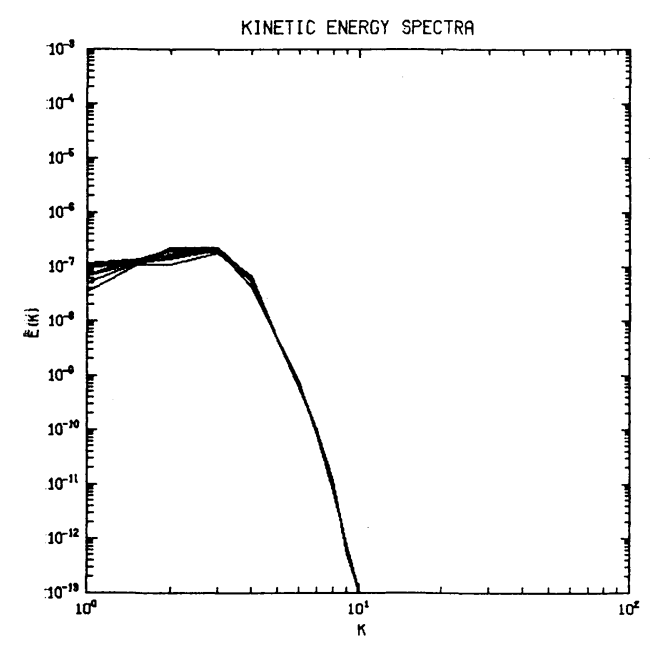

(c) at the equilibrium stage (see Fig. 4(d)). Decay of pure two-dimensional turbulence leads to $K^{-3}$ power law through entire wavenumber space (cf. Batchelor, 1969; Lilly, 1971). Unlike two-dimensional turbulence, spectral magnitudes slightly decrease toward smaller wavenumbers than $K_{p}$ in the present case. Upscale energy transfer seems to be restricted below

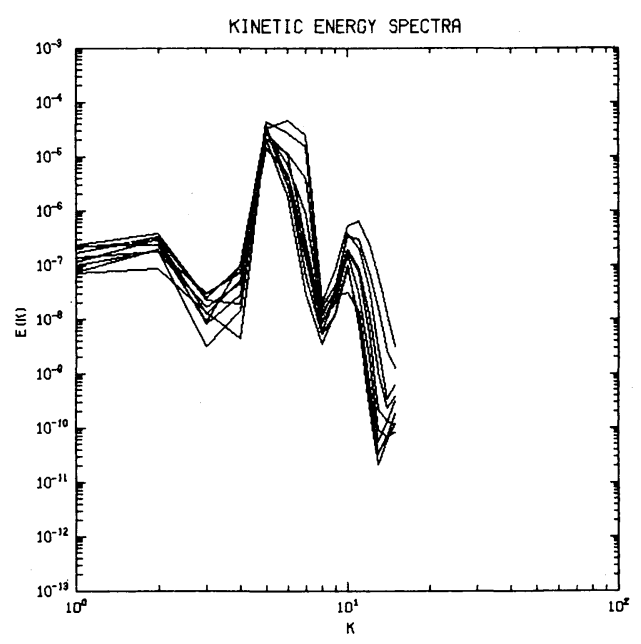

(b)

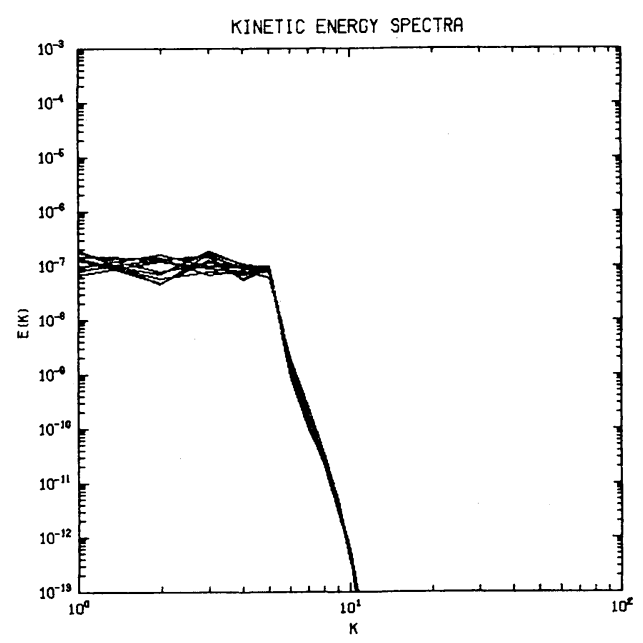

(d)

Fig. 8 Same as Fig. 4 but for kinetic energy spectra.
(a) Initial $(t=0)$
(b) $0-4500$ th time step $(0 \leqq t \leqq 13.5)$
(c) $45000-49500$ th time step $(135 \leqq t \leqq 148.5)$
(d) 75000-79500th time step $(225 \leqq t \leqq 238.5)$ 
$K_{p}$.

Spectral amplitude of geostrophic motions (or degenerated Rossby waves) is much smaller than that of (inertio-) gravity waves as shown in Figs. 5(a)-(d) and Figs. 6(a)-(d). This fact can be explained by remembering that the perturbed potential vorticity tends to disappear. Potential and kinetic energy spectra are fluctuating temporally still at final stages in the lower wavenumber domain, which means that the large-scale disturbances are keeping wave structure (see Figs. 7(a)-(d) and Figs. 8(a)-(d)).

\section{Concluding remarks}

Initially input gravity waves with random amplitudes and phases produce double scale or larger regular waves through nonlinear wavewave interactions when shallow water equations in the gravity wave regime are numerically integrated. The finally produced wavelike disturbances can be identified as largescale (inertio-) gravity waves. Geostrophic eddy motions are also generated but are negligibly weak. Upscale energy transfer is extensively suppressed in the lower wavenumber domain. Such features are quite different from those found in the two-dimensional turbulence and are important to understand the generation mechanism of large-scale (inertio-) gravity waves in the atmosphere and the oceans.

However, amplitudes of the finally produced waves are smaller by one order than those of initial disturbances. Therefore, it is not clear whether this mechanism of wave generation works well in the actual atmosphere and the oceans.

Forcing problem should be carried out in order to give an evidence why a $-5 / 3$ power spectrum is found frequently in the atmosphere as was described in the introductory chapter. We should also carry out numerical simulations changing $\varepsilon$ very widely. These problems are left for future investigations.

\section{Acknowledgements}

I wish to thank Doug Lilly for heartful discussions and encouragements through my stay at NCAR. I am also indebted to Akira Kasahara, Jack Herring, Jim McWilliams, Jo
Klemp, Dale Durran, Francis Bretherton, ChinHo Moen, and Yo Shigehisa for their helpful suggestions and discussions. Thanks are extended to John Wyngaard for giving me an oppotunity to use the CRAY-1 Computer. Deep insights on the present problem by Taroh Matsuno was very helpful to polish this paper. I owe Yumiko Suzuki for typing the manuscript.

\section{References}

Balsley, B.B. and D.A. Carter, 1982: The spectrum of atmospheric velocity fluctuations at $8 \mathrm{~km}$ and $86 \mathrm{~km}$. Geophys. Res. Lett., 9, 465-468.

Batchelor, G.K., 1969: Computation of the energy spectrum in homogeneous two-dimensional turbulence. High-speed computing in fluid dynamics. Phys. Fluids, Suppl. II, 223-239.

Bretherton, F.P., 1969: Momentum transport by gravity waves. Quart. J. Roy. Meteor. Soc., 95, 213-243.

Charney, J.G., 1971: Geostrophic turbulence. J. Atmos. Sci., 28, 1087-1095.

Chen, Q., 1982: The instability of the gravityinertia wave and its relation to low-level jet and heavy rainfall. J. Meteor. Soc. Japan, 60, 10411057.

Dunkerton, T.J., 1982: Stochastic parameterization of gravity wave stresses. J. Atmos. Sci., 39, $1711-1725$.

Gage, K.S., 1979: Evidence for a $k^{-5 / 3}$ law inertial range in mesoscale two-dimensional turbulence. J. Atmos. Sci., 36, 1950-1954.

Herring, J.R., S.A. Orszag, R.H. Kraichnan and D.G. Fox, 1974: Decay of two-dimensional homogeneous turbulence. J. Fluid Mech., 66, 417-444.

Holton, J.R., 1982: The role of gravity wave induced drag and diffusion in the momentum budget of the mesosphere. J. Atmos. Sci., 39, 791-799.

Kasahara, A., 1977: Numerical integration of the global barotropic primitive equations with Hough harmonic expansions. J. Atmos. Sci., 34, 687-701.

- 1982: Nonlinear normal mode initialization and the bounded derivative method. Rev. Geophys. Space Phys., 20, 385-397.

Kraichnan, R.H., 1967 : Inertial ranges in two-dimensional turbulence. Phys. Fluids, 10, 1417-1423.

- 1971: Inertial-range transfer in two-and three-dimensional turbulence. J. Fluid Mech., 47, $525-535$.

Klostermeyer, J., 1980: Computation of acousticgravity waves, Kelvin-Helmholtz instabilities, and wave-induced eddy transport in realistic atmospheric models. J. Geophys. Res., 85, 2829-2839.

Leith, C.E., 1968: Diffusion approximations for twodimensional turbulence. Phys. Fluids, 11, 671-674.

Lilly, D.K., 1969: Numerical simulation of twodimensional turbulence. Phys. Fluids, Suppl. II, 
240-249.

, 1971: Numerical simulation of developing and decaying two-dimensional turbulence. $J$. Fluid Mech., 45, 395-415.

Lindzen, R.S., 1981: Turbulence and stress due to gravity wave and tidal breakdown., J. Geophys. Res., 86, 9707-9714.

Matsuno, T., 1979: Topics in the middle atmosphere dynamics. Tenki, 26, 519-529 (in Japanese).

- 1982: A quasi-one-dimensional model of the middle atmosphere circulation interacting with internal gravity waves. J. Meteor. Soc. Japan, 60, 215-226.

Ogura, Y., 1952: The structure of two-dimension- ally isotropic turbulence. J. Meteor. Soc. Japan, 30, 59-64.

Orszag, S.A., 1971 : Numerical simulation of incompressible flows with simple boundaries: accuracy. J. Fluid Mech., 49, 75-112.

Pedlosky, J., 1979: Geophysical Fluid Dynamics. Springer-Verlag, New York, pp. 624.

Rhines, P.B., 1975: Waves and turbulence on a beta-plane. J. Fluid Mech., 69, 417-443.

Tanaka, H. and M.D. Yamanaka, 1984: Atmospheric circulation in the lower stratosphere induced by the mesoscale mountain wave breakdown. Submitted to J. Meteor. Soc. Japan.

\title{
重力波領域における浅水方程式の時間積分
}

\author{
田中 浩* \\ 大気科学研究センター, 米国
}

波動間の非線型相互作用に伴ならエネルギーの逆カスケードによって，(慣性）重力波が新らしく作られる かどらかを調べるために, 浅水方程式の重力波卓越領域における長時間皘分を実行した。純粋な二次元乱流に 見られる無制限なエネルギー逆カスケードと違って, 波動を合む場令はエネルギー逆カスケード自体が活発で なく，低い波数領域でむしろ抑制されることがわかる。初期值として与えられたランダムな振幅と位相をも つ重力波は最終的には非一様な波動状の擾乱を作る。これは重力波の大規模なものであることが同定できる。 しかしながら，これが現実の大気や海洋中で大規模な重力波を作るもつとも効果的な機構であるかどうかはさ だかではない。浅水波動に関する種々の特性についても詳細に述べられる。

*. 現所属 : 名古屋大学水圈科学研究所 